\title{
Theoretical Examination of the Pay-for-Performance Practice: Case of a Shipbuilding Company
}

\author{
+ Gyung-Ju Jun
}

† School of Business, Pusan National University, Busan, Korea

\begin{abstract}
Pay-for-performance plans are some of widely used human resource practices in many firms, including shipbuilding, for productivity and motivational improvement purposes. Such plans play an important role in industries that are highly labor-intensive, and where effective management of human resources is critical to business operations, such as the shipbuilding industry. Those practices can have large impact on employee performance and ultimately company competitiveness. Research studies that show how such incentive plans improve productivity and reported pattern of adoption by firms have spurred the use and adoption in many firms. However, there are also researchers who point out that there are negative consequences to using incentive plans. Therefore it is important for companies to carefully consider the practices they use. In this paper, I discuss research findings that support the practices and critical viewpoints related to pay-for-performance plans. Research findings from Korean literature are, then, discussed. The shipbuilding industry is chosen because proper human resource management is critical in reducing turnover and increasing employee satisfaction. Through a shipbuilding company case, problems related to using pay-for-performance incentive plans and how they affect work-related issues of employee morale, cooperation, and teamwork will be discussed. While positive aspects have been emphasized to drive greater adoption among firms, the resulting consequences of the pay plans need to be seriously considered and improvements upon the plans made by firms. Improvement suggestions are discussed in the conclusions and implications.
\end{abstract}

Key words : shipbuilding, pay-for-performance evaluation practice, compensation

\section{Introduction}

Organizational decision-makers confront issues and problems about pay: how to pay employees right, how to motivate them, how to increase satisfaction and productivity, or how to reduce certain employee-work related problems. With many environmental changes many firms competing globally have been pressed to structure and operate in accordance with prevailing trends in business practices. The compensation and evaluation systems used in many Korean firms that were developed or adopted were a shift away from the traditional seniority-based system of evaluating and paying employees and towards more Western, global methods. Companies shifted away from basing employee performance evaluation and compensation system on education level, tenure, age, etc. and towards a competency-based and contribution-based evaluation system that places more emphasis on individual performance and merit-pay (Chang, 2006). According to a study by the Ministry of Labor in 2011, 65\% of the companies with at least 100 employees were using merit-based pay annual salary system, which has been increasing annually since the 1997 economic crisis when Korean firms began adopting the system (Cho, 2011) and this is an increase from 48\% in 2005 (Chang, 2006). Adoption of merit-based compensation system in Korean firms is a result of global competition, greater need to have productive labor, and to increase motivation for individual employees restrained by rigid seniority-based pay system.

However, often companies are quick to adopt practices used by other companies domestically and globally without sufficient consideration of potential downside to some of the practices. In addition, when researchers examine case studies of compensation practices used by Korean companies, they usually describe the practices positively but provide inadequate discussion of negative effects of using the practices. However, it is important to have extensive discussion of the negative effects of the pay plans. The effects of the practices can become a negative force within the company, pulling productivity and work atmosphere down. The argument of the paper is that given the studies that show the negative consequences of using pay-for-performance plans, companies should consider the plans carefully before using them, and if they are currently using them, that some revisions and improvements to the plans are necessary to mitigate the negative effects on the employees. Companies need to weigh all the effects of using some of the popularly adopted practices beforehand.

\footnotetext{
† Corresponding author, gyungju1@hanmail.net 051)510-3151
} 
In this paper, the case of a shipbuilding company and its performance management system will be discussed briefly. The reason a shipbuilding company is used to illustrate pay-for-performance plan and related effects is that the shipbuilding industry is highly labor-intensive, and motivating and retaining employees is critical. Effective management of human resources and monitoring the effects of performance-based HR practices on employees and work atmosphere are highly important for shipbulding companies' global competitiveness. The shipbuilding industry in Korea in 2012 dominated 35\% of global market share, up from $33 \%$ in 2009, and has been world leader since 2008, (Kim and Chung, 2013; Chung and Lim, 2011; Park, 2010). The Korean companies in this industry initially grew to top position due to low-cost, intensive labor and sudden increase in demand for large ships, but with its growth the cost of labor increased including demand for better work conditions industry competitiveness is weakened (Park, 2010). During this time, major rival to Korean shipbuilding industry, China has begun to catch up and is threatening Korean companies' competitiveness (Park and Kim, 2012). Therefore, it is important that company leaders think about the problems and issues raised in the workplace, so that Korean companies can better compete. Ineffective work practices should be of concern for managers and they should work to make improvements so that companies are better equipped to compete in changing business environment.

In this paper, I will begin with a theoretical discussion of both supporting and opposing views in the effects of the performance evaluation and compensation practices. Brief discussion of Korean research evidence will follow. Then, the company overview will be given, followed by a discussion of its performance-based system and its effects in the company along with suggestions for improvement. The paper will conclude with some implications for companies and managers to take note of.

\section{Literature review on}

\section{pay-for-performance practices}

\subsection{Pay-for-performance practices}

The traditional, seniority-based compensation plan had an aspect of entitlement in which if an employee went to work and did just enough to avoid being fired, then he or she was entitled to the same size pay as everyone else doing the same job as that employee (Milkovich, Newman, and Gerhart, 2011,p.317). Pay-for-performance plan changed such compensation system and made pay vary with individual or organizational performance.

Some of the practices used by the company in this paper are management by objectives (MBO), balanced scorecard, and individual merit-based pay system which are all widely used human resource methods to affect individual and organizational productivity, employee involvement and satisfaction, and organizational commitment. Merit pay links increases in base pay with annual performance evaluation-how the individual is rated. At the end of the performance year, the employee is evaluated, usually by the direct supervisor, with the increase calculated into the base pay.

$\mathrm{MBO}$ is both goal setting and performance appraisal tool that has different variations across firms. It is a system in which people from top to bottom at every level of the organization set goals and each successively lower level identifies work objectives that will contribute to achieving organizational goals. It begins with strategic plan of the company, and the process flows down to the bottom levels, involving employees at all levels to contribute to organization's goals. The goals that are set become performance standards by which evaluations are conducted. At the beginning of the review period, the subordinate and supervisor discuss performance objectives, and at the end of the period, check on completion and achievement of those objectives. Performance rating is determined based on how much and well the objectives have been achieved.

In balanced scorecard approach, the organization combines performance measures directed toward the company's longand short-term goals and uses the results to determine the incentive amount. An organization may have financial goals, customer satisfaction goals, production goals, efficiency goals, employee learning goals, etc. to meet. Companies can customize performance evaluations according to job tasks and needs, product markets and customer needs using balanced scorecards. Balanced scorecards help communicate to employees about organization's goals and what it finds as important in performance evaluations and expects from employees.

\subsection{Research supporting pay-for-performance practices}

The kinds of behaviors employers find important are those 
that lead to achieving organizational goals and increasing performance. The strategy of organization determines the type of compensation policies and practices the organization chooses. Organizational leaders want to choose practices that produce the kinds of employee behaviors that move towards achieving organization's goals.

There are both sides of argument on the effectiveness of these practices. Pay-for-performance practices are chosen with the presumption that they are going to improve productivity, and there are numerous evidences to support the claim. Well-chosen practices of pay-for-performance have been shown to result in better employee and organizational performance (Heneman and Werner, 2005; McDonaly and Smith, 1995; Milkovich and Milkovich, 1992). Huselid (1995) studied link between high work performance practices and firm performance in nearly 1000 companies and found significant impact on employee outcomes such as employee turnover and productivity. Linking pay with performance paid off in this study. Examination of numerous studies showed that merit pay system helped increase performance when performance was tied to pay (Heneman and Werner, 2005). Gerhart and Milkovich (1999) studied 200 companies and found a positive relationship between size of the bonus and increase in return on assets. The variable portion of the pay, they found, had stronger impact on individual and organizational performance than the level of base pay. Evidence showing positive effect of some of the practices used by the company also exists. Merit pay has been shown in research to have small but significant impact on performance (Heneman, 1992). MBOs can have positive effect on company performance. In a thorough review of 70 research studies, it was found that in 68 of studies productivity gains occurred with the use of $\mathrm{MBO}$, and the level of commitment and support from top management was important in making it successful (Rodgers and Hunter, 1991). Positive effect of using balanced scorecard in a firm was reported in a study, and it was cautioned that the performance-related pay scheme had some impact but that it varied with firm characteristics and level of experience of managers (Griffith and Neely, 2009).

Because of reporting of positive findings of the effect of these plans on performance, companies have rallied behind the system and adopted them into their compensation system. However, the studies do not capture all the effects. We look at productivity figures to mainly determine if the system is working properly, but there are aspects of workplace that do not show up in productivity. In addition, more longitudinal studies are needed to account for the effect. The effects do not show up immediately after implementation. As will be illustrated in the case, there are problems that are hidden by more visibly captured performance figures such as financial and productivity. Level of the quality improvement in performance should also be examined.

\subsection{Research opposing pay-for-performance}

Often, organizational leaders believe that to motivate and satisfy employees, stimulating incentive system with proper compensation will resolve the issue. However, individual incentive pay undermines performance of both the individual and the organization (Pfeffer,1998). Pfeffer(1998) argued that managers were bought into expensive fictions about compensation and that many studies strongly suggest that individual incentive pay undermines teamwork, encourages a short-term focus, and leads people to believe that pay is not related to performance at all but to having the "right" relationships and an ingratiating personality (p.112). The "right" relationships, he referred to is trying to please one's supervisor, impression management, and having the networking skills. When one's performance evaluation result is dependent on supervisor's subjective assessment, individuals are likely to act in various ways to receive favorable evaluation. Pfeffer(1998), in addition, argues that people do not work for money, but they work for meaning in their lives and to have fun (p.112). The emphasis is on not treating people as mere productivity machines. Organizational performance is more than a sum of individual performance. Trying to pinpoint who exactly was responsible for exactly how much of that productivity is often more difficult or even impossible (Pfeffer, 1998). While individual merit-pay system is a popular practice among companies, it undermines teamwork and brings down employee morale and work atmosphere. Problems with merit-pay system are well-documented (Pearce, Stevenson and Perry, 1985; Hatcher and Ross, 1991; Wood, 1996). When company leaders do not take this into consideration, employees are basically treated as money-motivated people, and employees as a result lack loyalty and commitment (Pfeffer, 1998).

Other reasons cited by Kohn (1993) for opposing pay-for-performance plans require discussing. One reason is using pay to push employees to perform decreases intrinsic 
interest in the task itself. This is based on the view of Deci, Koestner, and Ryan (1999) who suggested that organizations need to be careful with using tangible rewards since using tangible rewards for completing or doing well in one's job is harmful to intrinsic motivation and task persistence. Rewards can be used as a technique of control, but it is because people are controlled by rewards that they become less intrinsically motivated (Deci, Koestner, and Ryan, 1999:657). When people receive rewards, the company, probably inadvertently, sends the message that it is an unpleasant task and that employees have to be lured into completing the task using rewards. The organization is essentially bribing the employees. Kohn (1999) argues that reward system in compensation can hurt productivity and rewarding employees for their work can reduce their intrinsic interest in the work itself. The extrinsic rewards reduce intrinsic reward of enjoying the work itself. This is also echoed by Pfeffer (1998b) who suggested that the organization is essentially bribing individuals to work.

Another reason is that pay is not the most motivating factor in people's minds. Often times, organizational leaders and managers assume that money is the most important issue in people's minds. According to a study of manager group and subordinate group in Citibank, the manager group was asked what they believe the subordinate group thought was most important extrinsic incentives and what the subordinate group actually responded as most important were examined. The manager group predicted that the subordinate group would be motivated chiefly by pay, security, and benefits (the extrinsic factors) and learning and worthwhileness of the job as the last motivating factors. But the result showed that the subordinate group responded in the opposite direction: learning and skills acquisition were at the top of the motivators and pay in the bottom of the list. Heath (1999) noted that overall the participants predicted that the manager and subordinate groups would be much more extrinsically motivated than they themselves were. This is probably due to lay theories that people have about others. One of the things the study showed is that either explicitly or implicitly, managers have inaccurate idea of how subordinates are motivated and are wrongly using incentives to motivate them. Pay-for-performance plan can frustrate employees who perform well and thus affecting their morale. Sometimes, there can be many good performers in the same group, and when some of those good performers do not receive rewards due to forced ranking and distribution in evaluation, it can bring down morale. The good performers are placed in lower rank because managers are forced to rank them in the lower category due to limits placed on percentages allotted for each grade level of performance. Lack of sufficient resources to support adequate allocation of rewards can also be a problem.

Another reason for opposing pay-for-performance is that rewards create tension in supervisor-subordinate relationships and among coworkers. Reward system causes employees to focus on getting the rewards at the expense of teamwork and cooperation. Everyone is seeking individual gain and creates a work atmosphere in which no one is trying to improve for collective gain (Kohn, 1993). This can lead to poor quality. When employees compete for rewards or recognition, not everyone is going to get the rewards and those who do not will feel similar to punishment (Kohn, 1993). Such attitude and atmosphere hinder cooperation and employees will see each other as obstacles to their own success (Kohn, 1993). While research evidence on both sides of the argument has not completely settled, some caution and flexibility are needed before blindly implementing incentive plans.

2.4

Korean research evidence

on pay-for-performance

The Korean companies' use of pay-for-performance plans dates back to the economic crisis in 1997. Korean firms had been using salary-based pay system that tied increases in pay with tenure in the company. However, such system reached its limits in changing global business environment and high labor cost (Kim, 2010; Kim, 2008). To better compete and manage their business environment, companies began to use pay-for-performance plans. Such plans in research studies showed to have positive effects but also produced negative side effects. Bae and Sa (2003) examined effects of high performance human resource management systems on organizational performance and found that such systems had positive effect on learning, internal processes, customer service and weak but positive relationship with financial performance. Yu and Park (2007) examined the effect of performance-based HRM practices on firm performance and found that many Korean firms adopted performance-based compensation plans due to institutional pressure rather than for strategic reasons. They found the performance-based HRM practices to improve firm performance. Chang (2003) studied the effect of compensation practices on work effort level of Korean employees. Ryu and Kim (2007) looked at the effect of how high-commitment HRM system on perceived organizational 
performance and found that there was a positive relationship between the two. However, these studies do not adequately cite potential negative side effects that can result from use of performance-based HR plans.

According to a 2007 Korea Labor Institute survey of 1,007 Korean firms' use of performance-based pay plans, firms using such plans were heavily concentrated in manufacturing, retail and wholesale goods, and service industries (Kim, 2008). When examining by industry, about $91 \%$ of the telecommunications firms surveyed, 87\%financial and insurance firms, $65.7 \%$ of retail and wholesale goods, $65 \%$ of service firms, and $50 \%$ of water, gas, electric firms were using such plans. Firms with large number of employees (1000-3000) were using the performance-based plans more so than firms with smaller than 300 employees. In addition, for over half of those surveyed, more firms without a union tended to use such plans than firms with unions.

As for reasons for using such plans, $63.8 \%$ of the firms surveyed responded that it is to motivate employees, $48.6 \%$ to clarify individual employee goals, $43.1 \%$ to reduce labor cost, and $42.6 \%$ to differentiate performance levels (Kim, 2008). Problems cited with regards to using perfomrance-based plans according to the KLI survey were low inter-rater reliability, difficulty in measuring performance depending on job categories, large gap in performance results between high and low performing employees, and employees avoiding work that cannot be measured in performance (Kim, 2008). Tables below show percentages of industries using performance-based plans, their cited reasons and problems cited with using performance-based plans from the survey.

Table 1 Firms Using Performance-based Plans by Industry and Reasons

\begin{tabular}{|c|c|c|c|c|c|c|}
\hline \multirow[t]{2}{*}{ Industry } & \multirow[t]{2}{*}{$\%$} & \multicolumn{5}{|c|}{$\begin{array}{l}\text { Reasons for using the plans } \\
\text { (duplicate answers allowed) } \\
\text { (\%) }\end{array}$} \\
\hline & & 1 & 2 & 3 & 4 & 5 \\
\hline Construction & 58 & 33 & 6 & 41 & 82 & 49 \\
\hline Manufacturing & 50 & 45 & 3 & 39 & 67 & 47 \\
\hline Water/Gas/Electricity & 20 & 50 & 0 & 50 & 0 & 50 \\
\hline Telecommunications & 91 & 20 & 0 & 20 & 70 & 20 \\
\hline Transportation & 40 & 46 & 0 & 54 & 68 & 46 \\
\hline Retail/Wholesale & 66 & 43 & 1 & 46 & 51 & 46 \\
\hline Finance/Insurance & 87 & 52 & 2 & 60 & 67 & 60 \\
\hline Real Estate & 65 & 11 & 11 & 44 & 67 & 22 \\
\hline Food/Lodging & 53 & 34 & 7 & 45 & 72 & 59 \\
\hline Services & 65 & 45 & 9 & 40 & 53 & 52 \\
\hline
\end{tabular}

Source: Adapted from Kim (2008)

Note: 1)To increase flexibility in performance measurement; 2)To decrease labor cost; 3)To link labor with performance; 4)To increase employee morale; 5)To clarify individual goals for employees.
Table 2 Problems with Using Performance-based Plans

\begin{tabular}{|c|c|}
\hline Problems & $\begin{array}{c}\text { \% of firms } \\
\text { responding } \\
\text { (duplicate } \\
\text { responses } \\
\text { allowed) }\end{array}$ \\
\hline Complexity in using performance tool & 15 \\
\hline $\begin{array}{l}\text { Difficulty in measuring performance for some } \\
\text { job tasks }\end{array}$ & 20 \\
\hline Large gap in low \& high performance results & 16 \\
\hline $\begin{array}{lcr}\text { Individual goal-achievement becoming } & \text { more } \\
\text { important than group-oriented } & \text { goal } \\
\text { achievements } & & \end{array}$ & 11 \\
\hline $\begin{array}{l}\text { Low inter-rater reliability in performance } \\
\text { measurement }\end{array}$ & 22 \\
\hline $\begin{array}{l}\text { Employees avoiding work difficult with } \\
\text { assessing perf. }\end{array}$ & 15 \\
\hline Difficult to assess job/work process & 22 \\
\hline
\end{tabular}

Source: Adapted from Kim (2008)

In the following case, these issues and problems resulting from use of pay-for-performance practice and extrinsic incentive system are discussed to further illustrate the problems that exist. I will begin with a brief overview of the company and its culture. Then, brief discussion of company's performance evaluation and compensation plan and problems arising from the practices will be discussed along with suggestions for improvement.

\section{Company D}

\subsection{Company overview}

Started in 1973 at Okpo Bay, Geoje Island, located on the southeastern tip of the Korean Peninsula, the shipyard of company D was completed in 1981. Company D has since grown into the world's premium shipbuilding and offshore contractor who is specialized in building various vessels, offshore platforms, drilling rigs, FPSO/FPUs, submarines, and destroyers. The shipyard which spans an area of 4.3 million meters squared encompasses the world's largest dock with a million-ton capacity and is optimized for building high-tech motor vessels using cutting-edge equipment, including a 900-ton goliath crane. The long-term goal of the company is to become world's best heavy industries group by 2020. It has 30,000 (including affiliates) employees.

Since reborn as an independent company in October 2000, company $\mathrm{D}$ has been creating a corporate culture on the core values of Trust and Passion. Company D defines "trust" as building partnerships and confidence with colleagues and 
within the organization through mutual respect and consideration, winning customer loyalty by honesty and promise-keeping, and strengthening trust between the employees and the company through transparent management. Company D defines "passion" as completing each task with determination and persistence, being responsible for one's actions with a sense of ownership, seeking continuous improvement for higher values instead of being complacent, and spreading the wings of self-actualization.

Company D has accomplished a lot in a short period of time since it became an independent company. Also, Company D became the first shipbuilder to deploy the Enterprise Resource Planning (ERP) system to secure transparent management, and it has established a process innovation system that increases management efficiency while eliminating waste through faster decision making. It received numerous awards for excellence in product quality, transparent management and corporate governance, cooperative labor-management relationship, and technological advances in its industry.

The company bases one of its core strengths on a strong corporate culture based on Trust and Passion with a strong belief that they cannot be created by a single person but needs active participation and cooperation of every individual. Company D expresses trust in the following ways: transparent management, mutual respect, information sharing, punctuality, respect for workers' rights, honesty, and harmony between labor and management. It espouses the following standards and principles: Keeping promises no matter how trivial they might be, thoroughly completing tasks at hand, recognizing each other's responsibility, talent and point of view, and having a symbiotic working relationship. With the second core value, passion, company D expresses it in the following ways: carrying out duties with enthusiasm and patience, adopting a pioneering spirit, and constantly seeking knowledge.

As for corporate culture, company $\mathrm{D}$ aims to create a workplace full of life and fun with unique ideas about people and outstanding ways to work and communicate ${ }^{--}$a lively workplace with trust, communication, and passion. It has belief in the wisdom that "happy employees make a happy company."

Performance management, evaluation and
compensation

The following performance evaluation method was adopted by company D in early 2000's and is systematically maintained year round. In January of each year, the company conducts performance evaluation by examining employee performance for the past year in contrast to the goals set. In February, using the results of the performance evaluation, company makes adjustments to employee salary and reflects the performance evaluation result for employee's career and training development purposes. In March, employees go through goal setting again following SMART guideline that prescribes setting realistic but challenging goals. The SMART guideline is an acronym that takes the first letter of five words that refer to: Space (space management), Method (structural efficiency, timing, and risk management that lead to innovations), Acquaintance (utilizing feedback from external stakeholders for better knowledge management), Result (goal management, compensation and performance management), and Time (maintaining balance between family and work life).

In the months of June and October, progress on goal achievement is reviewed with employees. Organizational and unit level goal achievement are looked at as well as meeting employees' personal goals. Goals set are reassessed in light of current situation. In the month of December, overall performance evaluation for the past year with regards to goal achievement is conducted. Employees' performance evaluation is inputted into the company portal system and salary and merit-based bonus are reflected in employee pay beginning in March. The company has stabilized performance evaluation and compensation system according to job categories. The company uses scorecard for goal management. It is similar to what other large conglomerate companies in Korea use. With balanced scorecards, the organization combines different performance measures that reflect company's long- and short-term goals and uses the results to determine the incentive amount. The company sets up job-specific productivity goals and other work attitude and behavior goals to meet. Companies customizes performance evaluations according to job tasks and needs.

The company's compensation is a reflection of corporate culture, philosophy of the top management, industry characteristics, employee motivation, and negotiation with the union. Nevertheless, there are still criticisms and employee dissatisfaction with this system because the number of reward recipients is few in number in comparison to the total number of employees. The company uses a system of fixed 
distribution of rewards where fixed percentages of recipients are allotted for each grade level of performance. The scale consists of 7 levels with fixed percentages for each level. In the highest levels $\mathrm{S}$ and $\mathrm{A}$, manager can allow a total fo $25 \%$ of employees for those ranks. The $\mathrm{B}$ level of performance group is allowed about $70 \%$, and $\mathrm{C}$ group is about $5 \%$. The lowest level of performance D group is not an obligatory assignment. Even when the manager may have high performers in the unit, he or she is forced to rank them in lower category due to forced ranking system of reward. That can have a negative effect on the high-performing individual who may feel helpless for being penalized due to an uncontrollable situation.

\subsection{Problems with the Practices \& Improvement Suggestions}

Though performance-based incentive plan has been noted to increase organizational commitment, other downsides have been found as in the case of this company. To better this system and increase employee satisfaction, the company can make a few adjustments. First, under such performance evaluation system the company has put a heavy emphasis on fast, visible results to meet short-term goals quickly. Compared to past performance evaluation under seniority-based system, under the MBO system sustained investment in company growth and intensive employee development are lacking. For example, employees in the R\&D unit should be placed under a different kind of performance evaluation and compensation system that places more emphasis on long-term rather than on short-term goal management and not place them under intense competition with one another. Such intensely competitive system results in less risk-taking, less innovative ideas, and more seeking of safer current product improvement ideas. Therefore, instead of mainly focusing on short-term objectives, the company needs to include mid- to long-term objectives in evaluating employee performance.

The issue of job insecurity arising from organizational restructuring and inadequate human resource development have produced decreased organizational commitment among employees from upper to lower level employees. For example, employees spend far less time mentoring and coaching new employees, an unwritten task that employees used to do as part of their job under previous performance evaluation system. The current employees are under such pressure to do their tasks that they can provide little on-the-job training to the new employees. In addition, their view of the new employees is not as team members but as competition. This type of mindset creates a competitive work atmosphere and employees are less likely to show cooperation and proper knowledge sharing. The company needs to ensure that nonspecified or unwritten work performed, competency development, and actions increasing company image and reputation are taken into factor when conducting performance evaluation.

Another is that results-oriented performance evaluation and results-based compensation has created overly competitive workplace atmosphere in which employees are less cooperative and doing less of knowledge sharing with one another and among units. Given that it is a heavy manufacturing firm in which teamwork is critical, such lack of cohesiveness among employees hurts company's effectiveness and less synergy effect results. The performance evaluation method needs to take into factor industry characteristics and firm competencies or organizational-level results when evaluating results and, then, secondarily evaluate individual employees' performance. The company needs to have a method in place to separately evaluate outstanding performance and competencies of individuals. This is to ensure that exceptional individuals do not lose motivation to succeed.

Systematic goal management is lacking. Validity and reliability problems with evaluation methods used and poor systematic management of performance results combined to create distrust among employees regarding performance evaluation. Difficulty in objectively and accurately evaluating employees' contribution and performance exists. Other criticisms with this method are problems in specifying contribution, job tasks that may be difficult to assess results for, lack of thorough evaluation process and feedback management all add to increase employee distrust in evaluation methods. In the minds of many employees there still exists seniority-based ranking among them that managers take into factor when evaluating. The organization needs to improve its method of collecting performance information and shift away from unilateral approach of giving feedback and instruction towards more interactional, transparent approach of discussing performance evaluation results between supervisor and subordinate.

Every year due to the limit the company has placed on the number of employees determined for promotion and salary 
increases, even employees with exceptional performance are restrained from receiving proper reward and compensation. This forced ranking and distribution method of evaluation has resulted in decline in morale and increase in dissatisfaction and frustration in employees. The company needs to move towards more flexible organizational structure where performance-based pay is determined regardless of structural limits. Rather than basing promotion on predetermined percentages, the company should flexibly apply different evaluation standards and possibly link promotion and reward with increase in revenue or profit. Forced distribution method of evaluation is accompanied by other problems of allotting well-performing employees into lower grade levels. This should be amended to give greater discretion to managers or supervisors to appropriately compensate and reward employees.

An auditing system that checks on objectivity and justness of evaluation process needs to be adopted. Procedural justice is important to reduce employee distrust and feeling of inequity. The scorecard system of setting and managing objectives should include other indirect measures of performance that may not immediately show up in numerical results but are still important in carrying out the tasks. Assessing employee's competencies in evaluation process is geared towards rewarding those with longer experience, and thus newer employees are placed under disadvantage. This type of system indirectly maintains the seniority-based reward system. Differentiation in reward system is needed for high-earning workers of high performance and for those who have long tenure.

\section{Conclusions and implications}

What has been illustrated through this company case is probably what are commonly experienced by many large Korean companies. Most companies continue to rely on incentive program because people do not take the time to examine the connection between incentive programs and problems with workplace productivity and morale (Kohn, 1993; Pfeffer, 1998). Rewards are a temporary fix and may look like they take care of the problem of productivity, but they need to be examined over the long term. When company leaders continue to hold on to the belief that the right incentive system can solve the motivational problems of employees, they will pay the cost in the long run. Pearce, Stevenson, and Perry $(1985: 263)$ noted that "although most scholars advocate performance contingent pay systems, they recognize that under certain conditions the implementation of such systems may be more dysfunctional than functional." Other scholars caution against using the pay-for-performance plan when trust levels are low, performance cannot be assessed validly, and distinctive differences in rewards do not exist (Lawler, 1981). Trust among employees affects group cohesiveness, and heightened group cohesiveness results in more committed behaviors and higher job satisfaction among employees (Kim, Cho and Shin, 2013). Therefore, shipbuilding companies should try to develop better practices that can bring out increased commitment and job satisfaction from employees through more trust-building practices. Employees' job satisfaction and turnover are affected by proper wages, working conditions, and career vision (Kim and Lee, 2011). Shipbuilding companies can help meet such needs by setting appropriate practices that reflect some of the research study results. Managers cannot observe all of the factors that affect their unit's performance and therefore under such circumstances subjective judgments by managers and objective unit performance data should be combined into a manager performance measure on which pay could be based (Pearce, Stevenson, and Perry, 1985:263).

Companies should ask if they have the organization structure sufficiently decentralized to allow different operating units to create flexible variations on a general pay-for-performance plan (Milkovich, Newman, and Gerhart, 2011). Different operating units may have different competencies and different competitive advantages and companies do not need to have a rigid pay-for-performance system that detracts from the advantages, all in the name of consistency, across divisions (Milkovich, Newman, and Gerhart, 2011:306). If the company leaders choose to continue with the plan, some flexibility and managerial discretion in application should be given also. Companies also should ask what matters to the employees or through exit interviews find out what was lacking or dissatisfying for employees and adjust compensation package to better meet needs of employees. Instead of assuming what they probably want, companies should ask employees how to best design the plan to fit their jobs and meet their needs. When Korean shipbuilding companies aim to hire long-term committed employees with high loyalty and job satisfaction, they can try to find out what characteristics prospective employees like or 
dislike about working in such organizations. If future studies can be conducted to discover some of the determining factors that motivate individuals to work in shipbuilding industry(Luksanato, 2013), Managers should take note of some of the suggestions made in this paper and understand that when they continue with a problematic HR system and do not properly give attention to these issues, work and employee-related problems will aggravate.

There was a lack of adequate information on the company related to before and after effects of introducing pay-for-performance plans, and it was prevented from examining further the effectiveness of such plans. Due to sensitivity of the information, such information was difficult to acquire. Future research studies can compare and analyze differences between the before and after effects. Studies of other labor-intensive industries that have used pay-for-performance plans to see if similar problems have occurred and what adaptations were made to lessen the problems related to the plan should be conducted to provide further understanding of use of the plans in Korean firms.

\section{Acknowledgments}

This study was supported by the Fund for Humanities \& Social Studies at Pusan National University 2011.

\section{References}

[1] Bae, J. S. and Sa, J. H.(2003), "The Effects of Human Resource Management Systems on Organizational Performance", Korean Journal of Management, Vol. 11, No. 3, pp. 133-169.

[2] Chang, E. M.(2003), "Effects of Individual Performance Based Compensation on Employees' Work Effort: In the Context of Commitment HR Bundles", Korean Journal of Management, Vol. 11, No. 1, pp. 133-158.

[3] Chang, S. I.(2006), "A Study on the MBO and BSC Performance Evaluation System- Focusing on the Orion Company", Korea Human Resource Development Journal, Vol. 8, No. 3, pp. 97-119.

[4] Cho, J. H.(2011), "Korea's Salary-Gainsharing System Since Adoption in 1997", Maeil Business Daily, September 16 .

[5] Chung, Y. K. and Lim, E. S.(2011), "National Economic Effects of Shipbuilding Industry", Journal of Korea Port Economic Association, Vol. 27, No. 1, pp. 129-143.

[6] Gerhart, B. and Milkovich, G.(1999), "Organizational
Differences in Managerial Compensation and Financial Performance", Academy of Management Journal, Vol. 33, No. 1, pp. 663-690.

[7] Griffith, R. and Neely, A.(2009), "Performance Pay and Managerial Experience in Multitask Teams: Evidence from within a Firm", Journal of Labor Economics, Vol. 27, No. 2, pp. 49-82.

[8] Hatcher, L. and Ross, L.(1991), "From Individual Incentives to an Organization-wide Gainsharing Plan Effects on teamwork and product quality", Journal of Organizational Behavior, Vol. 12, No. 2, pp. 169-183.

[9] Heath, C.(1999), "On the Social Psychology of Agency Relationships: Lay Theories of Motivation Overemphasize Extrinsic Incentives," Organizational Behavior and Human Decision Processes, Vol. 78, No. 1, pp. 25-62.

[10] Heneman, R. and Werner, J.(2005), Merit Pay: Linking Pay to Performance in a Changing World, Greenwich, CT, Information Age.

[11] Heneman, R.(1992), Merit Pay: Linking Pay Increases to Performance Ratings, Reading, MA, Addison-Wesley.

[12] Huselid, M. A.(1995), "The Impact of Human Resource Management Practices on Turnover, Productivity, and Corporate Financial Performance," Academy of Management Journal, Vol. 38, No. 3, pp. 635-672.

[13] Kim, J. H.(2008), "Pay-for-Performance Practice: Comparisons of Korea and Japan", Labor Review, Vol. 5, No. 2, pp. 41-54

[14] Kim, J. T., Cho, H. H. and Shin, Y. J.(2013), "A Study on the Effect of Swift Trust on the Cohesiveness and Organizational Effectiveness of Ship Organization", Journal of Korean Navigation and Port Research, Vol 37, No. 4, pp. 429-438.

[15] Kim, K. H. and Chung, C. H.(2013), "Other than the Big 3 (Hyundai, Samsung, DSME) the Shipbuilding Industry Reporting Losses", Chosun Ilbo, May 30.

[16] Kim, J. M. and Lee, D. H.(2011), "The Determinants of Turnover Intentions of Korean Seafarers", Journal of Korean Navigation and Port Research, Vol. 35, No. 3, pp. 219-226.

[17] Kim, S. S.(2010), High Performance HR system of Korean Companies, Seoul, SNU Press.

[18] Kohn, A.(1999), Punished by Rewards: The Trouble with Gold Stars, Incentive Plans, A's, Praise, and Other Bribes, Boston, Houghton-Mifflin.

[19] Kohn, A.(1993), "Why Incentive Plans Cannot Work", Harvard Business Review, Vol. 5, No. 4, pp. 54-63. 
[20] Lawler, E. E.(1981), Pay and Organization Development, Reading, MA, Addison-Wesley.

[21] Luksanato, S.(2013), "Determinants Affecting Thai Merchant Marine Students' Decision in Selecting a Maritime Institute in Thailand: Nautical Science Program", Journal of Korean Navigation Port Research, Vol. 37, No. 4, pp. 359-366.

[22] McDonaly, D. and Smith, A.(1995), "A Proven Connection: Performance Management and Business Results", Compensation and Benefits Review, Vol. 27, No. 4, pp. 59-64.

[23] Milkovich, G. T., Newman, J. M., and Gerhart, B. (2011), Compensation. New York, McGraw-Hill /rwin.

[24] Milkovich, G. and Milkovich, C.(1992), "Strengthening the Pay-performance Relationship: The Research", Compensation \& Benefits Review, Vol. 24, No. 1, 53-62.

[25] Pearce, J. L., Stevenson, W. B., and Perry, J. L.(1985), "Managerial Compensation Based on Organizational Performance: A Time Series Analysis of the Effects of Merit Pay", Academy of Management Journal, Vol. 28, No. 4, pp. 261-278.

[26] Pfeffer, J.(1998), "Six Dangerous Myths about Pay", Harvard Business Review, Vol. 3, No. 4, pp. 109-119.

[27] Park, S. H. and Kim, H. N.(2012), "The Change of Productivity and Efficiency of Korean Shipbuilding Industry and Its Determinants", Journal of Korea Port Economic Association, Vol. 26, No. 1, pp. 155-177.

[28 ]Rodgers, R. and Hunter, J. E.(1999), "Impact of Management by Objectives on Organizational Productivity," Journal of Applied Psychology, Vol. 76, No. 4, 322-336.

[29] Ryu, S. M. and Kim, S. S.(2007), "Environment, HR Involvement, HR System, HR Effectiveness, and Firms' Performance", Korean Journal of Management, Vol. 11, No. 2, pp. 1-43.

[30] Yu, G. C. and Park, W. S.(2007), "Determinants of Organizational Effectiveness of Performance-based Human Resource Management", Korean Journal of Management, Vol. 15, No. 2, pp. 187-224.

Received 1 October 2013

Revised 18 October 2013

Accepted 21 October 2013 